\title{
The Research and Implementation Scheme of Online Open Course Mode of "Comprehensive Integration" in Higher Vocational Education
}

\author{
Rong Zhu, Liming Zhao
}

Ningbo City College of Vocational Technology, Ningbo, Zhejiang, 315100

Keywords: online open courses; integration of reality and practice; higher vocational education; implementation plan

\begin{abstract}
In recent years, large-scale new online open courses have rapidly emerged, which is a major change in the teaching methods and learning methods of higher education, and also brings new opportunities and challenges for the reform and innovation of curriculum construction in higher vocational education. For higher vocational institutions as an important component of Chinese higher education, it is necessary to build an online open course with its own characteristics, in line with its own development characteristics, carry out research and exploration in the text and put forward implementation programs, to promote continuous innovations on higher vocational education with joint efforts.
\end{abstract}

\section{Introduction}

The online open course is a new type of open course. It is an online teaching course reconstructed by the learner and has complete instructional activities such as short teaching videos, homework, quiz, discussion, and examinations.

In recent years, new online open courses and learning platforms, such as online open courses ("MuCourse”), have risen rapidly around the world, expanding teaching time and space, enhancing teaching appeal, stimulating learners' enthusiasm and autonomy, and expanding The beneficiary aspect of high-quality educational resources has promoted the reform of teaching contents, methods, models, and teaching management system mechanisms, bringing new opportunities and challenges to the reform and development of higher education teaching.

In January 2012, Udacity was founded by a professor at Stanford University. In April 2012, two professors from Stanford University jointly created Coursera, a for-profit education technology company. In May 2012, MIT and Harvard University jointly created Large-scale open online classroom platform EDx; in 2013, Britain, Australia, France, Japan and other countries started MOOC construction in succession. At present, there are nearly 80 foreign MOOC platforms.

At the same time, in April 2012, Shanghai established the "University Course Sharing Center"; in May 2013, Tsinghua University and Peking University joined EDx; in July 2013, Shanghai Jiaotong University and Coursera established a partnership; 2013 In September of the same year, Huiyao.com and Yee.Net cooperated with Coursera and formally joined its global translation cooperation project. In October 2013, Netease announced cooperation with Coursera as its video hosting service provider; in October 2013, Tsinghua University’s "School "Online" was officially launched; in April 2014, "Good University Online" was officially released; in May 2014, "Love Course" website officially launched "Chinese University MOOC" and "Chinese Vocational Education MOOC".

The goal of building an online open curriculum is to accelerate the development of online open courses and platforms suitable for China's national conditions, promote the application of courses, and strengthen organization and management; on the other hand, it is to deepen the reform of higher education teaching and actively adapt to the individual development and diversification of learners. Lifelong learning needs, based on the national conditions to build online open courses and public service platform, strengthen the supervision of curriculum construction and public service platform operation, promote the deep integration of information technology and education and teaching, promote the application of quality education resources for sharing, and comprehensively improve 
the quality of education and teaching.

Therefore, in May 2015, the Ministry of Education promulgated documents to promote the construction and wide application of online open courses, integrate high-quality educational resources and technical resources, realize the application and sharing of various forms of courses and platforms, and promote education and teaching reform and education system innovation. , improve the quality of education and teaching. Build a number of high-quality online open courses represented by large-scale online open courses, curriculum application and teaching services, identify a group of national boutique online open courses, and identify more than 1,000 national boutique online open courses by 2017, by 2020 More than 3,000 national boutique online open courses were identified.

In November 2015, the Education Department of Zhejiang Province issued a notice to carry out provincial-level boutique online open course construction work. In 2015, it strived to develop 500 provincial-level boutique online open courses in 3 years. At the beginning of 2016, about 100 projects have been approved. The Open Online Platform for Quality Online Learning in Zhejiang Colleges and Universities has been put into operation.

In recent years, the government and universities have also launched online course platforms and curriculum resources into operation, and achieved significant results. On the "Love Course" website of the Ministry of Education, currently 432 courses have been launched on the "Chinese University MOOC" with a registered population of 4.38 million and a total of 13.46 million students have been selected; Tsinghua University's "School Online” has also launched a large number of online course learners. The "Superior League" mainly based on local colleges now has nearly 300 online courses and more than 20 shared schools. The Ningbo University Collegiate League Platform has currently launched 93 courses and has nearly 20,000 learners.

\section{The Problems in the Promotion and Application of Online Course in Higher Vocational Education}

From the perspectives of several online course platforms, such as Love Courses, School Online, Good University Online, and Good Class Alliance, which are widely used in China, the course and audience still follow the original characteristics of MOOC: curriculum is mainly based on subject theory, learners Discipline education is mainly for undergraduate and graduate students. Taking the "Love Course" platform as an example, it launched the "China University MOOC" and "China Vocational Education MOOC" channels, with 432 courses on the line, 4.38 million registered persons, and 13.46 million registered electors, with higher vocational education. Only 63 courses were put on the "China Vocational Education MOOC" channel. The number of registered people was only 840,000, and the cumulative number of elective courses was also 1.63 million. This is somewhat "asymmetrical" with the fact that the number of students in our higher vocational education accounted for the "half of the country" in higher education.

Where is the problem? We should analyze the two major elements of an online course. One is the course itself, and the second is the audience of the course. That is, the problem is that practice teaching has become the bottleneck of the promotion of online courses in higher vocational education. If we can clearly understand the inherent characteristics of online courses in higher vocational education and master the characteristics of learning in higher vocational students, we will be able to do a good job. "MOOC", an online course for higher vocational students.

Higher vocational education is education oriented to professional posts. The selection principle of theoretical knowledge in the curriculum system is "required and sufficient". At the same time, the teaching of theoretical knowledge and the way students apply knowledge are also accompanied by the need for work tasks. so knowledge is called "work knowledge."

Practice is the most important aspect of higher vocational education. No matter whether it is the ratio of classes or the way of implementation and assessment of the courses, the most courses in higher vocational education are "comprehensive integration courses". The teaching methods of higher vocational education are "doing high school” and "in learning”. Do "or "teaching to unite."

The context of the curriculum system and instructional design is "based on the work process," 
and the pursuit of teaching pursues "project references, task-driven". Students continue to improve their professional ability in practice.

The dissemination and application of online courses in China is still dominated by undergraduate colleges and their educators. Therefore, the current development model of online courses in China is oriented to subject education and knowledge-oriented education. Moreover, current training, lectures, and literature on online courses are mainly based on subject education. They do not reflect the curriculum characteristics of higher vocational education and do not take into account the learning characteristics of higher vocational students.

Through the analysis of online courses for major online courses in China, such as "China University MOOC”, "School Online”, “Good University Online” and "Excellent Class Alliance”, the proportion of general courses and subject theory courses accounted for over $85 \%$. The content of the course mainly involves theoretical knowledge, and there are very few courses on practical implementation of online teaching.

What about the online courses in higher vocational education? The "Comprehensive Integration" courses in the 63 courses on the "MOOC" channel of the Ministry of Education's love course "China Vocational Education MOOC" are also less than 50\%, and few of these "Comprehensive Integration" courses carry out "practical teaching” online. "' More, we still use the online / offline combination of processing practices. From the first batch of on-line courses (professionals) in Zhejiang Province, the first batch of courses (professionals) in Ningbo Muchao League, and three batches of school-based absenteeism in Ningbo City Vocational and Technical College, the basics and "China Vocational education MOOC" is consistent.

\section{The Implementation of the "Comprehensive Integration" Online Open Curriculum Model of Higher Vocational Education}

In today's vigorous development of vocational education, improve teachers' understanding of the practical and integrated teaching, and fully understand the importance of the scientific integration of the scientific teaching model for higher vocational talents. Combining theoretical learning with practical training, it focuses on cultivating students' hands-on abilities, building quality and skills training frameworks throughout the course, enriching classroom teaching and practical teaching, and improving teaching quality. In the integrated teaching process, teachers should comprehensively understand the careers that the students will engage in in the future, set teaching content according to the characteristics of the profession, solve problems that may arise in the students' future work, improve students' professional skills, and give full play to the students' Ability to improve student interest in learning and develop comprehensive learning capabilities.

First of all, the team members of the course must undertake the teaching tasks of the course for a long time in the teaching frontline. Support and encourage teaching teachers and famous experts to give lectures. In addition to lecturers, they must also be equipped with necessary assistant teachers and modern education technicians, be able to build online long-term service courses, undertake course content updates, online counseling, and answer questions. The course team should be responsible for the training and teaching seminars of the relevant teachers of the course. Secondly, the integrated teaching of realism has a relatively high requirement for teachers' teaching ability. Teachers must be proficient in using various teaching tools and equipment to correctly guide students. At the same time, teachers must keep abreast of new technologies and theories in the industry, and apply these new technologies and theories in a timely manner. In classroom teaching, so as to improve their professional skills and overall quality.

The use of a practical and integrated teaching method should highlight the importance of practical teaching, and must establish a practical and scientific teaching environment in a scientific and rational manner. Only in this way can students' interest in learning be improved, and students can be truly integrated into practical teaching so as to give full play to the integration of practice and practice. The main role of teaching. On-line courses must be integrated with the teaching characteristics and needs of the overall teaching design. Curriculum design, teaching arrangements and presentation are in line with the needs of learners' mobile learning and blended learning. 
To truly realize the integration of teaching and learning in curriculum teaching, it is imperative to write and use a practical and integrated teaching material. Second, we must adopt a variety of teaching methods in teaching, so that we can achieve truth, reason and reason.

In the teaching activities of online courses, it is necessary to actively conduct the learning of case-based, blended, inquiry-based and other teaching modes, embedding online tests via web pages, instant online coaching questions, online and offline discussions, online job submission and correction, and online community discussions. And so on, to promote resource sharing, problem communication, and collaborative learning among teachers and students. A diversified learning evaluation system was established to explore a combination of online and offline integration, a combination of process skills assessment and summative assessment of the multiple assessment assessment model to promote student autonomy learning, process learning and experiential learning. For higher vocational students, it is recommended that the curriculum scores be comprehensively assessed by the usual assessment, process skills assessment and theoretical assessment. This will not only attach importance to the assessment of the theory but also to the evaluation of the skills, thereby contributing to the cultivation of students' professional skills.

\section{Conclusion}

The current theory-based model of online courses does not match the characteristics of higher vocational courses and cannot meet the needs of higher vocational education. Practical teaching has become the bottleneck of the development of online courses in higher vocational education. Therefore, the research and exploration of the online course model of "integration and integration" of higher vocational education courses has become an urgent task, and only by solving this problem can the online courses be applied in the core curriculum of higher vocational education, and then be widely promoted.

\section{Acknowledgements}

Fund Project: 2016 National Educational Technology Planning Project Project No.: 166233250

2016 Zhejiang Province Higher Education Classroom Teaching Reform Research Project Project No.: kg20160905

\section{References}

[1] Zhang Yupeng. Status quo and countermeasures of college online open course construction [J]. China E-education, 2015(2):5-7.

[2] Tan Yuanyuan. On-line open curriculum construction specification discussion [J]. New West (theory), 2015 (3): 120-121.

[3] Xu He. Research on Online Open Course Construction Plan[J]. Journal of Advanced Studies, 2016(5):109-110.

[4] Guan Weihong, Hua Chi, Chen Yu. Research on the construction of online open class hybrid teaching mode based on WeChat public platform, 2016(22):42-45.

[5] Li Zhiyong. Research on the Development of Online Course Construction in Higher Vocational Colleges[J]. Science Research Forum,2016:44-46. 